\title{
Secondary nipple reconstruction using two surgical techniques
}

\author{
Jae-Ho Chung ${ }^{1}$, Da-Som Kim ${ }^{1}$, Hyun-Dong Yeo ${ }^{1}$, Seung-Pil Jung ${ }^{2}$, Seung-Ha Park ${ }^{1}$, Eul-Sik Yoon ${ }^{1}$ \\ Departments of ${ }^{1}$ Plastic and Reconstructive Surgery and ${ }^{2}$ Breast and Endocrine Surgery, Korea University Anam Hospital, Seoul, Korea
}

\begin{abstract}
Background Although the initial projection after primary nipple reconstruction is excellent, nipple projection gradually flattens in most cases due to multiple causes. Although various methods have been reported to rebuild the nipple after nipple flattening, the most effective method of secondary nipple reconstruction remains unknown. The aim of this study was to review our institution's experiences with secondary nipple reconstruction.

Methods We conducted a retrospective review from March 2012 to January 2019. We performed secondary nipple reconstruction if the primary reconstructed nipple height differed by more than $6 \mathrm{~mm}$ from the normal nipple height. We chose the method of nipple revision according to the degree of tissue scarring and the remaining nipple projection.

Results We performed secondary nipple reconstruction on a total of 27 nipples, using pursestring sutures for 19 nipples and star flaps in eight nipples. The median follow-up period was 8 months (range, 6-19 months) after the final nipple reconstruction. Among the 19 nipples reconstructed using purse-string sutures, 10 (53\%) demonstrated acceptable projection of more than $5 \mathrm{~mm}$. Among the eight nipples reconstructed using star flaps, six (75\%) showed acceptable projection of more than $5 \mathrm{~mm}$. Most of the patients (73\%) were satisfied (scores of 4 or 5) with the nipple reconstruction overall.

Conclusions Few studies have presented favorable outcomes of secondary nipple reconstruction. When the star flap and purse-string suture methods were used depending on the remaining nipple height and scarring, appropriate projection could be achieved.
\end{abstract}

Keywords Nipples / Reconstructive surgical procedures / Surgical flaps

\author{
Correspondence: Eul-Sik Yoon \\ Department of Plastic and \\ Reconstructive Surgery, Korea \\ University Anam Hospital, 73 \\ Goryeodae-ro, Seongbuk-gu, Seoul \\ 02841 , Korea \\ Tel: $+82-2-920-5368$ \\ Fax: +82-2-922-7437 \\ E-mail: yesanam2@korea.ac.kr
}

\section{INTRODUCTION}

Reconstruction of the nipple-areolar complex in breast reconstruction is a very important process in terms of postoperative psychological and/or aesthetic satisfaction. Multiple studies have demonstrated that patients' satisfaction with breast reconstruction largely depends on the presence of the nipple-areolar complex $[1,2]$. Nipple reconstruction also plays an important role in psychosocial function [3]. Therefore, nipple reconstruc- tion is the last step when completing breast reconstruction.

Nipple reconstructive surgery is usually done 3 to 6 months after breast reconstruction with the goal of creating a nipple similar to that on the contralateral side. Several methods for nipple reconstruction, such as grafting, local flaps, internal nipple prostheses, and autogenous implants, have been introduced during the past 30 years [4]. In the early days, methods such as skin grafts or contralateral nipple grafts were mainly used. However, in recent years, the most common technique is a local flap 
using autologous tissue without damaging the opposite nipple. Several "pull-out" local flap techniques using breast tissue, such as the star flap, C-V flap, and bell flap, have been reported [5-9].

Although the initial projection after primary nipple reconstruction with these techniques is excellent, projection gradually flattens in most cases. Shestak et al. [6] compared the star, skate, and bell flaps and showed a flattening rate of 30\%-75\% within a 2 -year follow-up period. Nipple flattening is a multifactorial phenomenon, with causes including an insufficient amount of subcutaneous fat, pressure (both internal and external), poor flap design, and tissue memory.

To date, several studies have reported methods of secondary nipple revision [10-13]. Nahabedian [11] used local flaps and AlloDerm (LifeCell Corp.) to augment nipple projection. Kim and Ahn [10] restored nipple projection by burying four triangular dermal flaps. However, there is still no consensus on when to perform secondary nipple reconstruction and which method to choose. The objective of this study was to review our institution's experiences with secondary nipple reconstruction and to propose a surgical strategy for nipple revision.

\section{METHODS}

\section{Patients}

This retrospective study was approved by the Institutional Review Board of Korea University Anam Hospital (IRB No. 2020AN0174). We retrieved the clinical details of all patients who underwent secondary nipple reconstruction at our hospital from March 2012 to January 2019 from their medical records, including detailed operation notes and a photography database. In this 7-year period, the senior author performed 138 primary nipple reconstructions. Of these, 27 nipples (19.6\%) required secondary reconstruction due to excessive flattening, defined as a difference of more than $6 \mathrm{~mm}$ from the height of the opposite nipple. The patients provided written informed consent for the publication and the use of their images.

\section{Surgical techniques}

We performed the surgical technique for each patient using either a star flap or purse-string suture according to an assessment of tissue scarring and the remaining nipple projection. Specifically, if the remaining nipple showed excessive flattening of less than $2 \mathrm{~mm}$ in height, a purse-string suture or star flap was used depending on the scarring. However, if the remaining nipple had a height of more than $2 \mathrm{~mm}$, a purse-string suture was used. The degree of scarring in the tissue was checked through the pinch test (Fig. 1). A nipple projection of over $5 \mathrm{~mm}$ was defined as acceptable, because the average height of the nipple was reported to be approximately $5 \mathrm{~mm}$ [14].

\section{Star flap method}

We usually performed the operation under local anesthesia using lidocaine without epinephrine. We outlined the superior star flap by placing the remaining nipple in the center in order

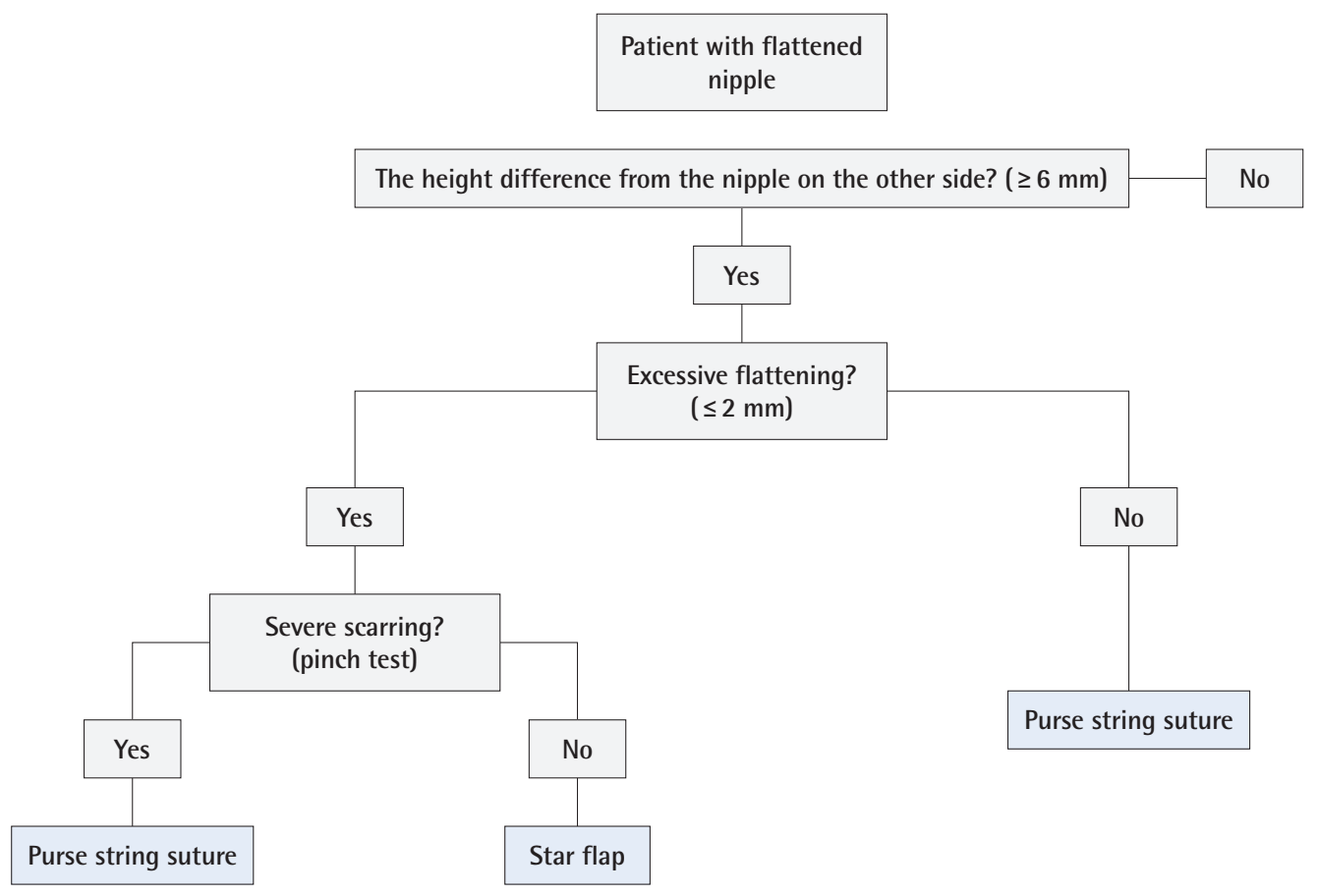

Fig. 1. A treatment algorithm for patients presenting with a flattened nipple. 

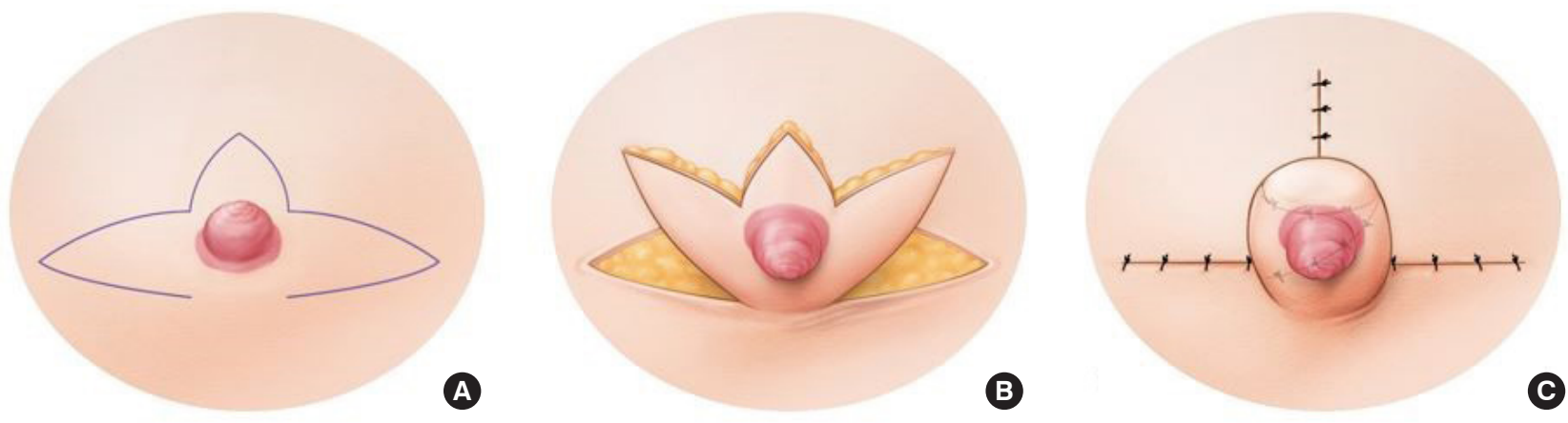

Fig. 2. Schematic illustration of a superiorly based star flap. (A) We outlined the superiorly based star flap by placing the remaining nipple in the center in order not to change the position of the existing nipple, while preventing constriction of the lower pole of the breast. (B) We made the skin incision and elevated the star flap in the subcutaneous plane, incorporating some fat while checking the viability of the central and lateral limbs. (C) The lateral limbs were first wrapped and sutured to each other. Then, we placed the central limb on top to complete the nipple reconstruction. Finally, the flap donor wounds were closed.

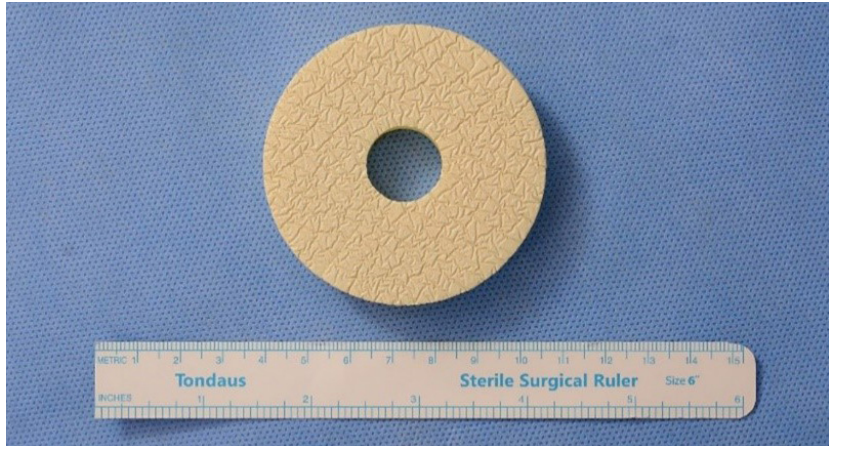

Fig. 3. Doughnut-shaped foam dressing for prevention of compressive forces. Doughnut-shaped foam (Ildong Pharmaceutical Co., Ltd.) was used to reduce external pressure, one of the causes of nipple flattening.

not to change the position of the existing nipple while preventing constriction of the lower pole of the breast (Fig. 2A). When outlining, the length of each part depended on the width of the base and the extent of the projection of the opposite nipple, since the base width of the new nipple must be the same as that of the opposite nipple. In star flaps, the width of the lateral limbs is the final determinant of nipple projection. When deciding on the preoperative design and size, it should be expected that the projection may be reduced by $30 \%$ to $40 \%$ over time. For this reason, we recommend that the lateral limbs have a width of at least $1.5 \mathrm{~cm}$ and a length of $2 \mathrm{~cm}$ or more, and that the total height of the nipples is at least $1 \mathrm{~cm}$.

We made the skin incision and elevated the star flap in the subcutaneous plane, incorporating some fat (Fig. 2B). Upon ensuring the viability of the central and lateral limbs, we first wrapped the lateral limbs and sutured them to each other using polydioxanone 4-0 (PDS II; Ethicon, Raritan, NJ, USA). We then placed the central limb on top to complete the nipple reconstruction (Fig. 2C). We closed the flap donor wounds of the lateral limbs primarily using Vicryl 4-0. Following nipple reconstruction, we used a doughnut-shaped foam (Ildong Pharmaceutical Co., Seoul, Korea) for approximately 1 month to mitigate projection loss caused by early compressive forces (Fig. 3).

\section{Purse-string suture method}

We also performed this procedure under local anesthesia using lidocaine without epinephrine. Eight small (approximately 1 $\mathrm{mm}$ each) curvilinear skin incisions were spaced evenly along the margin of the existing nipple with a no. 11 blade scalpel (Fig. $4 \mathrm{~A})$. We then placed a polypropylene 3-0 suture in one direction through the previously created skin incisions, starting at the 12 o'clock position. This was maintained relatively deep to prevent the suture from becoming extruded or visible through the skin. We completed the purse-string suture where both ends met at the 12 o'clock position (Fig. 4B). We then achieved the desired nipple projection by countering the radial pull of the surrounding tissue. Finally, we closed the curvilinear incisions with Prolene 6-0 sutures (Fig. 4C).

\section{Questionnaire and assessment}

We measured and photographed nipple projection in the operating room and the clinic. At postoperative 3 months, patients were asked to evaluate their level of satisfaction regarding the secondarily reconstructed nipple with a 5-point Likert scale ( 1 = very poor, 2 = poor, $3=$ fair, $4=$ good, and $5=$ excellent $)$.

\section{Statistical analysis}

All statistical analyses were carried out using SPSS version 24.0 software (IBM Corp., Armonk, NY, USA). The Mann-Whitney $\mathrm{U}$ test, independent t-test, and Fisher exact test were used for statistical comparisons between groups. For all analyses, a P-value $<0.05$ was considered to indicate statistical significance. 

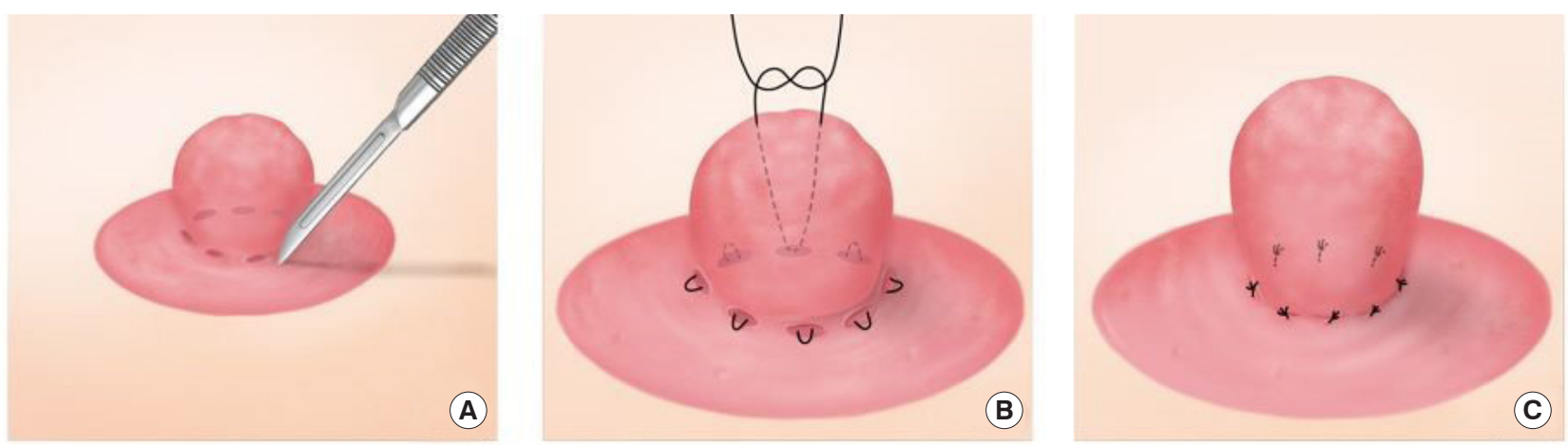

Fig. 4. Schematic illustration of the purse-string suture technique. (A) Eight small (approximately $1 \mathrm{~mm}$ each) curvilinear skin incisions were spaced evenly along the margin of the existing nipple with a no. 11 blade scalpel. (B) We then placed a polypropylene 3-0 suture in one direction through the previously created skin incisions, starting at the 12 o'clock position. This was maintained relatively deep to prevent the suture from becoming extruded or visible through the skin. We completed the purse-string suture where both ends met at the 12 o'clock position. (C) Next, we achieved the desired nipple projection by countering the radial pull of the surrounding tissue. Finally, we closed the curvilinear incisions with Prolene 6-0 sutures.

\section{RESULTS}

\section{Patient demographics and operative information}

We analyzed a total of 27 patients, including eight who underwent surgery with the star flap technique and 19 who had surgery with the purse-string suture technique. There were no significant differences between these two groups in age (49.2 years for the star flap group vs. 54.5 years for the purse string group; $\mathrm{P}=0.176)$, body mass index $\left(24.0 \mathrm{~kg} / \mathrm{m}^{2}\right.$ for the star flap group vs. $24.4 \mathrm{~kg} / \mathrm{m}^{2}$ for the purse string group; $\mathrm{P}=0.781$ ), comorbidities, breast reconstruction type, or the number of patients who received radiation therapy. Table 1 summarizes the patient demographics and operative information.

Patients' mean age and the median follow-up period after the final reconstruction were 50.8 years (range, 33-66 years) and 8 months (range, 6-19 months), respectively. The types of breast reconstruction were implants in 11 breasts, autologous tissue in 13 breasts, and autologous tissue with implants in three breasts. Data on nipple projection before and after surgery, the time for the final projection height of the nipple, and the types of procedures performed are provided in Table 2. Of the eight patients who received a star flap as the secondary reconstruction method, the primary reconstruction method was a star flap in three cases, a C-V flap in three cases, and a skate flap in two cases. Instead, most patients who received a purse-string suture as the secondary reconstruction method had received a C-V flap as the primary method (14/19). In all nipples, wound healing was uneventful, without skin flap necrosis or local infection .

\section{Outcomes of secondary nipple reconstruction}

According to the authors' algorithm, 19 patients received pursestring sutures and eight received star flaps. Of the 19 nipples
Table 1. Patient demographics

\begin{tabular}{lccc}
\hline \multirow{2}{*}{ Variable } & \multicolumn{2}{c}{ Technique } & \\
\cline { 2 - 3 } & Star flap & $\begin{array}{c}\text { Purse-string } \\
\text { suture }\end{array}$ & \\
\hline No. of patients & 8 & 19 & \\
Age (yr) & $54.5 \pm 6.6$ & $49.2 \pm 9.7$ & 0.18 \\
BMl (kg/m $\left.{ }^{2}\right)$ & $23.95 \pm 2.18$ & $24.36 \pm 3.82$ & $0.78^{\text {a) }}$ \\
Comorbidities & & & \\
$\quad$ Hypertension & $1(12.5)$ & $1(5.3)$ & $0.51^{\text {b) }}$ \\
$\quad$ Diabetes & $1(12.5)$ & $1(5.3)$ & $0.51^{\text {b) }}$ \\
$\quad$ Active smoker & 0 & 0 & $\mathrm{NA}$ \\
Breast reconstruction type & & & 0.64 \\
$\quad$ Implant & $2(25.0)$ & $9(47.4)$ & \\
$\quad$ Autologous & $6(75.0)$ & $7(36.8)$ & \\
$\quad$ Implant + autologous & 0 & $3(15.8)$ & \\
Adjuvant radiotherapy & 0 & $1(5.3)$ & $1.00^{\text {b) }}$ \\
\hline
\end{tabular}

Values are presented as the mean \pm SD or number (\%). BMI, body mass index; NA, not available.

a)Mann-Whitney U test; ')Fisher exact test.

with purse-string sutures, 10 (52.6\%) demonstrated acceptable projection. Among the eight nipples with star flaps, six (75.0\%) demonstrated acceptable projection. Figs. 5 and 6 illustrate the clinical results of our patients in each group.

Specifically, in the cases of secondary nipple reconstruction using the purse-string suture method, the mean nipple height was $2.9 \mathrm{~mm}$ prior to secondary nipple reconstruction and 4.7 $\mathrm{mm}$ at an average follow-up of 10.9 months. In contrast, for secondary nipple reconstruction cases using the star-flap method, the mean nipple height was $1.8 \mathrm{~mm}$ prior to secondary nipple reconstruction and $6.0 \mathrm{~mm}$ at an average follow-up of 8.4 months. The preoperative projection before secondary reconstruction showed a statistically significant difference between the two groups, because we considered whether the remaining nipple projection was more than $2 \mathrm{~mm}$ when selecting which 
Table 2. Characteristics of patients and operative information

\begin{tabular}{|c|c|c|c|c|c|c|c|c|c|}
\hline \multirow[b]{2}{*}{$\begin{array}{l}\text { Patient } \\
\text { No. }\end{array}$} & \multirow[b]{2}{*}{$\begin{array}{l}\text { Age } \\
(y r)\end{array}$} & \multicolumn{2}{|c|}{ Procedure } & \multicolumn{3}{|c|}{ Primary nipple reconstruction } & \multicolumn{3}{|c|}{ Secondary nipple reconstruction } \\
\hline & & $\begin{array}{c}\text { Breast } \\
\text { reconstruction }\end{array}$ & $\begin{array}{c}\text { Primary/secondary } \\
\text { nipple } \\
\text { reconstruction }\end{array}$ & $\begin{array}{l}\text { Initial } \\
\text { projection } \\
(\mathrm{mm})\end{array}$ & $\begin{array}{l}\text { Final } \\
\text { projection } \\
(\mathrm{mm})\end{array}$ & $\begin{array}{l}\text { Time } \\
\text { (mo) }\end{array}$ & $\begin{array}{l}\text { Initial } \\
\text { projection } \\
(\mathrm{mm})\end{array}$ & $\begin{array}{l}\text { Final } \\
\text { projection } \\
(\mathrm{mm})\end{array}$ & $\begin{array}{l}\text { Time } \\
\text { (mo) }\end{array}$ \\
\hline 1 & 58 & LD + implant & CV/PS & 10 & 2 & 24 & 8 & 5 & 7 \\
\hline 2 & 50 & Implant & SF/PS & 11 & 5 & 5 & 10 & 6 & 8 \\
\hline 3 & 34 & Implant & CV/PS & 10 & 2 & 24 & 7 & 6 & 6 \\
\hline 4 & 50 & LD + implant & SF/PS & 9 & 2 & 48 & 6 & 4 & 6 \\
\hline 5 & 51 & Implant & CV/PS & 10 & 3 & 6 & 9 & 4 & 12 \\
\hline 6 & 53 & MS-2 TRAM & SkF/SF & 10 & 2 & 24 & 10 & 8 & 7 \\
\hline 7 & 56 & MS-2 TRAM & CV/PS & 10 & 3 & 5 & 8 & 6 & 6 \\
\hline 8 & 57 & LD & $\mathrm{SF} / \mathrm{SF}$ & 8 & 2 & 12 & 8 & 7 & 6 \\
\hline 9 & 41 & Implant & CV/PS & 8 & 2 & 24 & 5 & 2 & 15 \\
\hline 10 & 33 & Implant & CV/PS & 9 & 2 & 6 & 7 & 5 & 7 \\
\hline 11 & 59 & DIEP & CV/PS & 10 & 4 & 11 & 8 & 4 & 9 \\
\hline 12 & 36 & LD & CV/PS & 10 & 5 & 4 & 9 & 6 & 8 \\
\hline 13 & 53 & Implant & CV/PS & 10 & 5 & 4 & 9 & 5 & 10 \\
\hline 14 & 60 & MS-2 TRAM & CV/SF & 10 & 2 & 12 & 10 & 4 & 6 \\
\hline 15 & 63 & MS-2 TRAM & CV/SF & 10 & 2 & 8 & 10 & 6 & 19 \\
\hline 16 & 52 & Implant & CV/PS & 9 & 4 & 3 & 7 & 6 & 6 \\
\hline 17 & 53 & MS-2 TRAM & CV/PS & 10 & 2 & 7 & 10 & 4 & 10 \\
\hline 18 & 48 & Implant & CV/PS & 10 & 3 & 3 & 9 & 8 & 6 \\
\hline 19 & 66 & LD & CV/PS & 10 & 2 & 5 & 8 & 6 & 6 \\
\hline 20 & 50 & Implant & CV/SF & 8 & 2 & 5 & 9 & 5 & 19 \\
\hline 21 & 52 & MS-2 TRAM & SF/PS & 9 & 2 & 6 & 7 & 2 & 9 \\
\hline 22 & 34 & Implant & SF/PS & 9 & 2 & 7 & 7 & 3 & 10 \\
\hline 23 & 58 & Implant & $\mathrm{SF} / \mathrm{SF}$ & 10 & 1 & 45 & 10 & 7 & 10 \\
\hline 24 & 42 & MS-2 TRAM & SkF/SF & 10 & 1 & 7 & 10 & 4 & 8 \\
\hline 25 & 48 & DIEP & CV/PS & 10 & 5 & 6 & 8 & 4 & 10 \\
\hline 26 & 53 & MS-2 TRAM & SF/SF & 10 & 2 & 24 & 10 & 7 & 12 \\
\hline 27 & 62 & LD + implant & SF/PS & 10 & 1 & 12 & 6 & 3 & 9 \\
\hline
\end{tabular}

LD, latissimus dorsi; MS-2 TRAM, muscle sparing-2 transverse rectus myocutaneous; DIEP, deep inferior epigastric perforator; CV, C-V flap; PS, purse string; SF, star flap; SkF, skate flap.
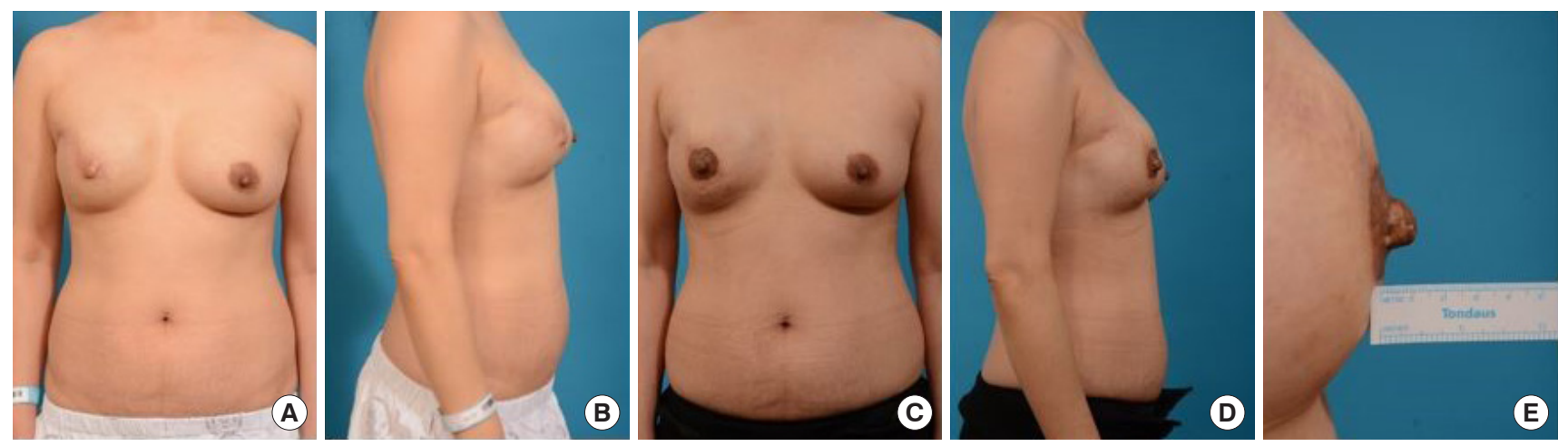

Fig. 5. Secondary nipple reconstruction using purse-string suture (patient no. 18). A 48-year-old woman who underwent two-stage breast implant reconstruction received a star flap for primary nipple reconstruction. (A, B) At 3 months after primary nipple reconstruction, nipple projection had flattened (estimated projection, $3 \mathrm{~mm}$ ). At this time, secondary nipple reconstruction using a purse-string suture was performed. (C, D) At 6 months after secondary nipple reconstruction, the nipple demonstrated acceptable projection (estimated projection, 8 mm). (E) Enlarged view of the reconstructed nipple.

method to use. However, with regard to final nipple height, acceptable projection (more than $5 \mathrm{~mm}$ ) could be achieved in both groups (Table 3).

\section{Comparison with opposite nipple projection}

Table 4 summarizes the data for the height of the reconstructed nipple and the opposite nipple measured at the last follow-up. 

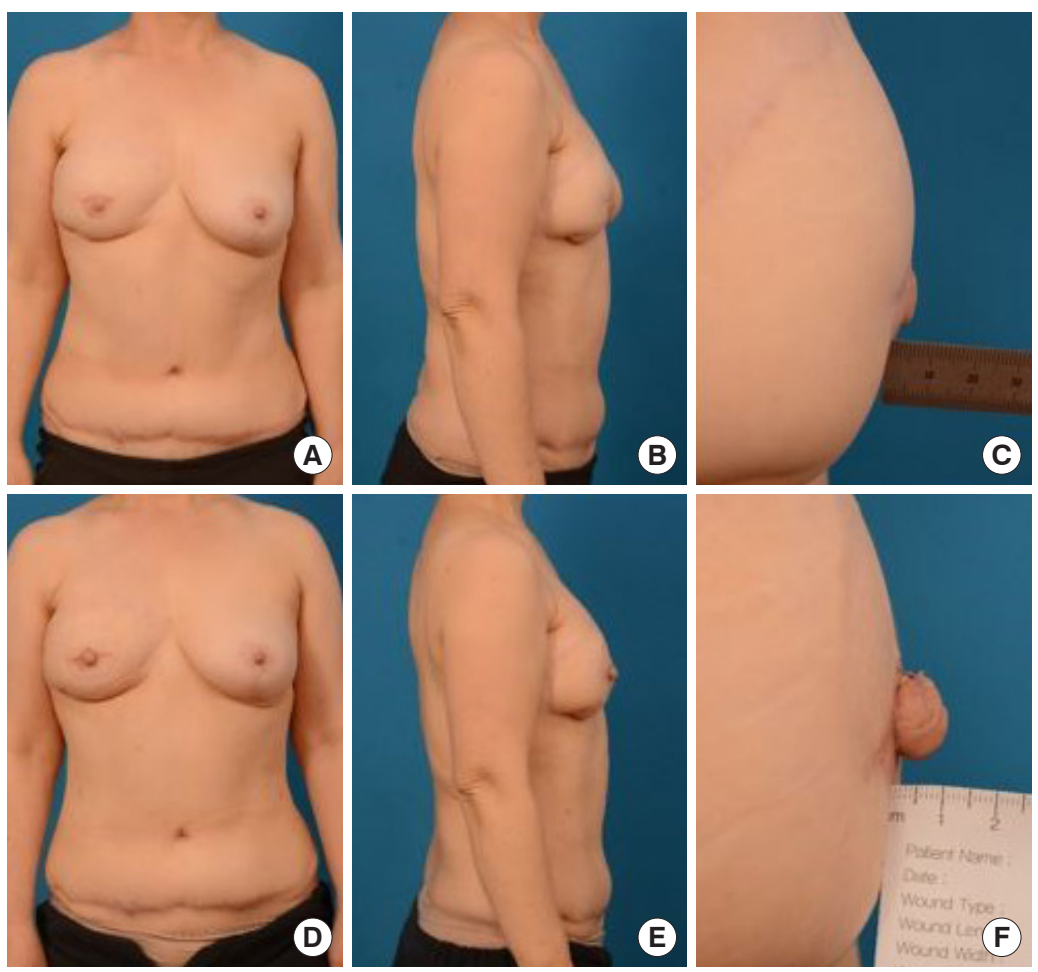

Fig. 6. Secondary nipple reconstruction using a star flap (patient no. 6). A 53-year-old woman who underwent a muscle sparing-2 transverse rectus abdominis musculocutaneous flap received a C-V flap for primary nipple reconstruction. (A-C) At 2 years after primary nipple reconstruction, nipple projection had flattened $(2 \mathrm{~mm}$ ). At this time, secondary nipple reconstruction using a star flap was performed. (D-F) At 7 months after we performed a star flap for secondary nipple reconstruction, the nipple demonstrated acceptable projection (8 $\mathrm{mm}$ ).

Table 3. Outcomes of secondary nipple reconstruction

\begin{tabular}{lccc}
\hline \multirow{2}{*}{ Outcome } & \multicolumn{2}{c}{ Technique } & \\
\cline { 2 - 3 } & Star flap & $\begin{array}{c}\text { Purse-string } \\
\text { suture }\end{array}$ & P-value \\
\hline Preoperative projection (mm) & $1.8 \pm 0.5$ & $2.9 \pm 1.3$ & $0.025^{\mathrm{a}, c, c}$ \\
Final projection (mm) & $6.0 \pm 1.5$ & $4.7 \pm 1.6$ & $0.055^{\mathrm{b})}$ \\
Follow-up time (mo) & $8.4 \pm 2.4$ & $10.9 \pm 5.4$ & $0.252^{\mathrm{b})}$ \\
\hline
\end{tabular}

Values are presented as the mean \pm SD.

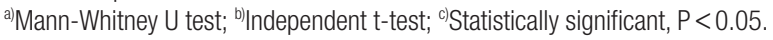

At an average of 12.9 months after secondary nipple revision, the reconstructed nipple was $5.1 \mathrm{~mm}$ high, the opposite nipple was $6.3 \mathrm{~mm}$ high, and there was a significant difference between the two values $(\mathrm{P}=0.036)$.

\section{Patient satisfaction}

Patients were asked to assess the aesthetic outcomes of the reconstructed nipples overall on a 5-point Likert scale $(1=$ very poor, 2 = poor, $3=$ fair, $4=$ good, and $5=$ excellent) and a higher score indicated greater satisfaction [15]. The mean satisfaction score was 4.07 (range, 2-5). Most of the patients (73.1\%) were satisfied (scores of 4 or 5) with the nipple reconstruction overall (Table 5).

\section{DISCUSSION}

Reconstructed breasts play a major role in maintaining the femininity of breast cancer patients, as the nipple completes the naturalness and symmetry of reconstructed breasts. Nipple reconstruction helps the patient recognize that her body is intact, even if it is not fully anatomically restored. Breast surgeons might consider nipple reconstruction to be a minor procedure. However, the result is significant, in that it can change the outcome of the entire breast reconstruction. No matter how perfectly reconstructed the breast is, if the nipple is asymmetric or unnatural, it will be unacceptable to the patient. If reconstruction of the nipple is successful, the overall outcome of the breast reconstruction can be more natural and satisfactory. Thus, reconstruction of the nipple is the final step when completing breast reconstruction.

However, reconstructed nipples have a natural tendency to flatten, with the skin surface returning to its normal contour. Nipple flattening is a multifactorial phenomenon, with causes including an insufficient amount subcutaneous fat, pressure (both internal and external pressure), poor flap design, delayed healing, and tissue memory [11]. Wearing a bra may cause external pressure on the breast surface, predisposing it to nipple 
Table 4. Comparison with opposite nipple projection

\begin{tabular}{|c|c|c|c|c|c|c|}
\hline \multirow[b]{2}{*}{ Patient No. } & \multirow[b]{2}{*}{ Age (yr) } & \multicolumn{2}{|c|}{ Procedure } & \multicolumn{2}{|c|}{ Final projection (mm) } & \multirow{2}{*}{$\begin{array}{l}\text { Time from secondary nipple } \\
\text { reconstruction (mo) }\end{array}$} \\
\hline & & $\begin{array}{c}\text { Breast } \\
\text { reconstruction }\end{array}$ & $\begin{array}{l}\text { Secondary nipple } \\
\text { reconstruction }\end{array}$ & Reconstructed nipple & Opposite nipple & \\
\hline 1 & 58 & LD + implant & PS & 5 & 5 & 24 \\
\hline 2 & 50 & Implant & PS & 6 & 6 & 5 \\
\hline 3 & 34 & Implant & PS & 6 & 6 & 24 \\
\hline 4 & 50 & LD + implant & PS & 4 & 3 & 48 \\
\hline 5 & 51 & Implant & PS & 4 & 10 & 6 \\
\hline 6 & 53 & MS-2 TRAM & SF & 8 & 10 & 24 \\
\hline 7 & 56 & MS-2 TRAM & PS & 6 & 6 & 5 \\
\hline 8 & 57 & LD & SF & 7 & 7 & 12 \\
\hline 9 & 41 & Implant & PS & 2 & 10 & 24 \\
\hline 10 & 33 & Implant & PS & 5 & 3 & 6 \\
\hline 11 & 59 & DIEP & PS & 4 & 5 & 11 \\
\hline 12 & 36 & LD & PS & 6 & 7 & 4 \\
\hline 13 & 53 & Implant & PS & 5 & 9 & 4 \\
\hline 14 & 60 & MS-2 TRAM & SF & 4 & 8 & 12 \\
\hline 15 & 63 & MS-2 TRAM & SF & 6 & 6 & 8 \\
\hline 16 & 52 & Implant & PS & 6 & 9 & 3 \\
\hline 17 & 53 & MS-2 TRAM & PS & 4 & 2 & 7 \\
\hline 18 & 48 & Implant & PS & 8 & 10 & 3 \\
\hline 19 & 66 & LD & PS & 6 & 6 & 5 \\
\hline 20 & 50 & Implant & SF & 5 & 4 & 5 \\
\hline 21 & 52 & MS-2 TRAM & PS & 2 & 2 & 6 \\
\hline 22 & 34 & Implant & PS & 3 & 3 & 7 \\
\hline 23 & 58 & Implant & SF & 7 & 6 & 45 \\
\hline 24 & 42 & MS-2 TRAM & SF & 4 & 5 & 7 \\
\hline 25 & 48 & DIEP & PS & 4 & 10 & 6 \\
\hline 26 & 53 & MS-2 TRAM & SF & 7 & 7 & 24 \\
\hline 27 & 62 & LD + implant & PS & 3 & 6 & 12 \\
\hline Mean \pm SD & & & & $5.1 \pm 1.6$ & $6.3 \pm 2.5$ & $12.9 \pm 12.1$ \\
\hline
\end{tabular}

LD, latissimus dorsi; MS-2 TRAM, muscle sparing-2 transverse rectus myocutaneous; DIEP, deep inferior epigastric perforator; PS, purse string; SF, star flap.

Table 5. Patients' satisfaction with the secondarily reconstructed nipple

\begin{tabular}{lccccc}
\hline & \multicolumn{5}{c}{ Patients' satisfaction } \\
\cline { 2 - 6 } Technique & $\begin{array}{c}1 \\
\text { (very poor) }\end{array}$ & $\begin{array}{c}2 \\
\text { (poor) }\end{array}$ & $\begin{array}{c}3 \\
\text { (fair) }\end{array}$ & $\begin{array}{c}4 \\
\text { (good) }\end{array}$ & $\begin{array}{c}5 \\
\text { (excellent) }\end{array}$ \\
\hline Purse-string suture (n) & 0 & 2 & 5 & 6 & 6 \\
Star flap (n) & 0 & 0 & 1 & 1 & 6 \\
\hline
\end{tabular}

flattening. In addition, implants apply internal pressure, resulting in stretching and flattening of the breast surface over time. Other factors, such as inadequate subcutaneous fat and poor flap design, can impair circulation in local flaps, leading to delayed healing and eventual flattening. The natural processes of contraction inherent to wound healing also cause the projection of the reconstructed nipple to flatten [6,11]. Jabor et al. [16] found that an excessively flattened nipple was the key area of dissatisfaction after nipple reconstruction in more than $50 \%$ of the women whom they surveyed. Therefore, it is conventional to overcorrect the nipple relative to the opposite nipple projec- tion considering long-term outcomes.

Several techniques have been devised to resolve the issue of nipple flattening after nipple reconstruction. However, flattening remains an unsolved problem $[12,13,17,18]$. Some patients may eventually require secondary nipple reconstruction to regain projection and to correct flattened reconstructed nipples. Various methods have been used to rebuild secondary nipples. Nahabedian [11] introduced a technique of secondary nipple reconstruction using local flaps and acellular dermal grafts. Kim and Ahn [10] reported a nipple revision technique that involves anchoring dermal flaps. However, it is unknown which method is the most effective in specific cases of secondary nipple reconstruction.

Of the several local flaps, the star flap can include more tissue than can the C-V flap, because the central limb is also V-shaped. Unlike the skate flap, primary repair of the donor site is possible. For this reason, we chose the star flap as a local-flap method for secondary nipple reconstruction. Implementing star flaps on nipples showing excessive flattening after primary nipple recon- 
struction can produce acceptable long-term results. In our study, among the eight nipples with star flaps, six (75\%) demonstrated acceptable projection.

However, the star flap is not always applicable, such as in patients with severe scarring. If the flattening was not extreme or the scarring was severe, we performed the purse-string suture technique for secondary nipple reconstruction instead of a star flap. The purse-string suture technique is reproducible and does not require a separate skin-graft harvest for areola creation [19-21]. Of the 19 nipples with purse-string sutures, 10 (53\%) demonstrated acceptable projection.

Patient satisfaction is also associated with tattooing. We usually perform tattooing more than 3 months after the nipple revision, so most patients are not tattooed at the third month after nipple revision, which is when their satisfaction was evaluated. Therefore, in our study, patient satisfaction was related to nipple projection rather than tattooing.

Based on these experiences, we devised an algorithmic approach for secondary nipple reconstruction (Fig. 1). Given the favorable results in this study, we believe that good surgical outcomes can be achieved by our method of deciding on nipple reconstruction according to the degree of scarring in tissue and the remaining nipple projection.

Our study has several limitations. First, we did not compare this cohort of patients with a control group. However, considering that the average nipple height of women is $5 \mathrm{~mm}$, the final outcomes were satisfactory, with comparable postoperative projections [14]. Second, the difference in the follow-up period and the remaining height of the nipple just before nipple revision for each patient might have affected the final outcomes. However, in most cases, the remaining height of the nipple was less than $2 \mathrm{~mm}$, and the average follow-up period was more than 6 months, which was the period during which nipple projection would gradually achieve a stable plateau $[6,7,10]$.

We obtained good results by performing a star flap if the scarring was not severe and a purse-string suture in severe cases. It is possible to achieve balance with the opposite nipple by performing secondary nipple reconstruction using a proper method, thereby achieving aesthetic goals and increasing patient satisfaction. In this regard, the algorithm proposed herein could be a guide for secondary nipple reconstruction.

\section{NOTES}

\section{Conflict of interest}

No potential conflict of interest relevant to this article was reported.

\section{Ethical approval}

The study was approved by the Institutional Review Board of Korea University Anam Hospital (IRB No. 2020AN0174) and performed in accordance with the principles of the Declaration of Helsinki. Informed consent was waived because of the retrospective nature of the study and the analysis used anonymous clinical data.

\section{Patient consent}

The patients provided written informed consent for the publication and the use of their images.

\section{Author contribution}

Conceptualization: ES Yoon. Data curation: HD Yeo, SP Jung, SH Park. Formal analysis: HD Yeo. Methodology: DS Kim. Project administration: DS Kim. Visualization: DS Kim. Writing original draft: HD Yeo, DS Kim. Writing - review \& editing: JH Chung.

\section{ORCID}

$\begin{array}{ll}\text { Jae-Ho Chung } & \text { https://orcid.org/0000-0002-8351-2444 } \\ \text { Da-Som Kim } & \text { https://orcid.org/0000-0003-4413-7626 } \\ \text { Hyun-Dong Yeo } & \text { https://orcid.org/0000-0002-5499-5053 } \\ \text { Seung-Pil Jung } & \text { https://orcid.org/0000-0003-3967-2974 } \\ \text { Seung-Ha Park } & \text { https://orcid.org/0000-0002-2667-2791 } \\ \text { Eul-Sik Yoon } & \text { https://orcid.org/0000-0001-5734-6625 }\end{array}$

\section{REFERENCES}

1. Goh SC, Martin NA, Pandya AN, et al. Patient satisfaction following nipple-areolar complex reconstruction and tattooing. J Plast Reconstr Aesthet Surg 2011;64:360-3.

2. Wellisch DK, Schain WS, Noone RB, et al. The psychological contribution of nipple addition in breast reconstruction. Plast Reconstr Surg 1987;80:699-704.

3. Momoh AO, Colakoglu S, de Blacam C, et al. The impact of nipple reconstruction on patient satisfaction in breast reconstruction. Ann Plast Surg 2012;69:389-93.

4. Farhadi J, Maksvytyte GK, Schaefer DJ, et al. Reconstruction of the nipple-areola complex: an update. J Plast Reconstr Aesthet Surg 2006;59:40-53.

5. Losken A, Mackay GJ, Bostwick J 3rd. Nipple reconstruction using the C-V flap technique: a long-term evaluation. Plast Reconstr Surg 2001;108:361-9.

6. Shestak KC, Gabriel A, Landecker A, et al. Assessment of long-term nipple projection: a comparison of three techniques. Plast Reconstr Surg 2002;110:780-6.

7. Few JW, Marcus JR, Casas LA, et al. Long-term predictable 
nipple projection following reconstruction. Plast Reconstr Surg 1999; 104:1321-4.

8. Chia HL, Wong M, Tan BK. Nipple reconstruction with rolled dermal graft support. Arch Plast Surg 2014;41:15862.

9. Kroll SS, Reece GP, Miller MJ, et al. Comparison of nipple projection with the modified double-opposing tab and star flaps. Plast Reconstr Surg 1997;99:1602-5.

10. Kim JH, Ahn HC. A revision restoring projection after nipple reconstruction by burying four triangular dermal flaps. Arch Plast Surg 2016;43:339-43.

11. Nahabedian MY. Secondary nipple reconstruction using local flaps and AlloDerm. Plast Reconstr Surg 2005; 115:2056-61.

12. Bernard RW, Beran SJ. Autologous fat graft in nipple reconstruction. Plast Reconstr Surg 2003;112:964-8.

13. Tanabe HY, Tai Y, Kiyokawa K, et al. Nipple-areola reconstruction with a dermal-fat flap and rolled auricular cartilage. Plast Reconstr Surg 1997;100:431-8.

14. Park IY, Kim MR, Jo HH, et al. Association of the nippleareola complexes with age, parity, and breastfeeding in Korean premenopausal women. J Hum Lact 2014;30:474-9.
15. Harcourt D, Russell C, Hughes J, et al. Patient satisfaction in relation to nipple reconstruction: the importance of information provision. J Plast Reconstr Aesthet Surg 2011;64:494-9.

16. Jabor MA, Shayani P, Collins DR Jr, et al. Nipple-areola reconstruction: satisfaction and clinical determinants. Plast Reconstr Surg 2002;110:457-65.

17. Guerra AB, Khoobehi K, Metzinger SE, et al. New technique for nipple areola reconstruction: arrow flap and rib cartilage graft for long-lasting nipple projection. Ann Plast Surg 2003;50:31-7.

18. Yanaga H. Nipple-areola reconstruction with a dermal-fat flap: technical improvement from rolled auricular cartilage to artificial bone. Plast Reconstr Surg 2003;112:1863-9.

19. Caterson SA, Singh M, Talbot SG, et al. Reconstruction of areolar projection using a purse-string suture technique. Plast Reconstr Surg Glob Open 2015;3:e453.

20. Peled IJ. Purse-string suture for nipple projection. Plast Reconstr Surg 1999;103:1480-2.

21. Weinfeld AB, Somia N, Codner MA. Purse-string nipple areolar reconstruction. Ann Plast Surg 2008;61:364-7. 